\title{
The DSM: mindful science or mindless power? A critical review
}

\author{
Bassam Khoury ${ }^{1}$, Ellen J. Langer ${ }^{1}$ and Francesco Pagnini ${ }^{1,2,3}$ \\ 1 Department of Psychology, Harvard University, Cambridge, MA, USA \\ 2 Department of Psychology, Catholic University of Milan, Milan, Italy \\ ${ }^{3}$ Niguarda Ca' Granda Hospital, Milan, Italy
}

\section{Edited by:}

Angelo Compare, University of

Bergamo, Italy

\section{Reviewed by:}

Claudia Cormio, National Cancer Research Institute Giovanni Paolo II, Italy

Gabriele Roberto Cassullo, University of Turin, Italy

\section{*Correspondence:}

Bassam Khoury, Department of

Psychology, Harvard University,

33 Kirkland Street, Cambridge,

MA 02138, USA

e-mail: bkhoury@fas.harvard.edu
In this paper we review the Diagnostic and Statistical Manual of mental health (DSM), its scientific bases and utility. The concepts of "normality," "pathology," and boundaries between them are critically reviewed. We further use the concepts of mindfulness and mindlessness, and evidence from cognitive and social sciences to investigate the DSM clinical and social impact and we argue against its assigned overpower. We recommend including alternative perspectives to the DSM, such as mindfulness and positive psychology. We also argue for including mindfulness training in psychiatric residency and clinical psychology programs.

\section{Keywords: DSM, mindful, mindless, mindfulness, normality, pathology, utility}

\section{THE DSM}

The Diagnostic and Statistical Manual of Mental Disorders (DSM) is considered the most important document for the diagnosis and the classification of mental disorders. Despite the existence of alternative diagnostic criteria and approaches [e.g., International Statistical Classification of Diseases (ICD), Psychodynamic Diagnostic Manual (PDM)], the DSM criteria remain the gold standard for mental health diagnosis. It is published by the American Psychiatric Association (APA), whose initial objective was to establish a nosology of mental disorders that can constitute a common language among clinicians, researchers, health insurance companies, and the pharmaceutical industry. Five versions and two revisions of the manual were published since 1952, the last one being its fifth edition published in May 18, 2013. Since its first draft, the DSM went through many modifications. For example the number of proclaimed mental disorders went from 108 in its first version (1952), to 182 in DSM-II published in 1968, to 265 in DSM-III published in 1980, followed by its revision DSM-III-R in 1987 with 292 diagnoses, to 354 categories in the DSM-IV published in 1994, followed by its revision DSM-IV-R in 2000 with no significant modifications, and lastly the DSM-5, which did not change significantly the number of disorders but rather the criteria (or thresholds) of diagnoses, leading to a potential inflation of some diagnosis up to 28\% (Keely et al., 2008; Corcoran and Walsh, 2010; Millon et al., 2010; Frances, 2013; Greenberg, 2013). Along with the increasing number of disorders, the manual went from 130 pages in its first edition to 886 pages in its fourth and 991 in its current edition, this was accompanied with a substantial growth in the price, sales, and revenues of DSM for the APA reaching between $\$ 5$ and $\$ 6$ million annually, almost $10 \%$ of its global revenue (Greenberg, 2013, p. 110). The income from the DSM for the APA is very trivial in comparison with the income for the pharmaceutical industry, which exceeds $\$ 18$ billion a year in sales of psychotropic medication, with more than $\$ 12$ billion a year from antidepressants sales only (Frances, 2013, p. 89). Beyond the numbers and facts concerning the DSM, which were extensively addressed elsewhere (e.g., Frances, 2013; Greenberg, 2013), there is an ongoing debate inside the scientific and clinical communities about the DSM science and utility. This papers aims to shed more light on the science and utility of the DSM categories, while suggesting other possibilities and alternative approaches.

\section{THE SCIENCE AND UTILITY OF THE DSM}

A central aim of the DSM taskforce was to set appropriate cutoff points between what is considered "normal" from what is "pathological," in order to treat the individuals belonging to the latter category. The concept of pathology is an aprioristic definition, originally based on statistical distribution (the "S" in DSM), with an arbitrary decision that is not scientifically driven (Frances, 2013, p. 24). In fact, the criteria set for cut-offs between "normal" and "pathological" (e.g., number of symptoms, frequency and duration of symptoms, and nature/duration of dysfunction associated with the proclaimed disorder) are also "arbitrary" and subjective because there is no laboratory test or biological markers to set the boundary between "normal" and "pathological." In addition, there is not scientific link between basic science (e.g., cognitive, neurological and social science) and clinical psychiatry. Second, cultures differ dramatically in their conception of normality; what is "normal" in one culture can be considered "abnormal" or "pathological" in another one. In addition, there are significant within-and-between cultural differences in the manner in which diagnostic categories are interpreted and diagnostic labels are used (e.g., Zubin, 1967; Rosenhan, 1973; Crow, 1986; Zinbarg et al., 1994; Keller et al., 1995). For example, the APA defined homosexuality as a mental disorder until the DSM-II in 1973 (Greener, 2013). Third, manifestations (named symptoms in the DSM) 
and behaviors are contextually embedded and vary dramatically according to the situation, for example, aggressive behavior can be well-adapted in one context but not in another one. Even if the DSM partially addresses this issue, subtle contextual differences may create several diagnostic biases. Last, when normality is set in relationship to the ability of understanding reality (i.e., in the definition of psychosis and dissociative disorders), it is arguable that reality itself is constantly changing and hard or even impossible to grasp.

From another side, studies regarding the prevalence of mental disorders using the DSM categories did not provide coherent results, as it would be expected. In fact, there are several differences when comparing the prevalence rates obtained. For example, retrospective studies suggested that the annual prevalence of DSM psychiatric disorders is around 30\% in adults younger than 55 years and projected a lifetime prevalence rate of $50 \%$ for a psychiatric disorder by 75 years of age (Kessler et al., 2005). However, these rates seem to be an underestimation as evidence of forgetting is common for recall beyond 6 months (e.g., Harlow and Linet, 1989; Pillemer and White, 1989; Angold and Costello, 1996). Therefore, prospective studies can be more accurate (Moffitt et al., 2010; Copeland etal., 2011). Using prospective methodology, the cumulative prevalence of DSM-IV defined categories among 1037 individuals during a 15-year prospective longitudinal study (between age 18 and 32 ) yielded to $50 \%$ for an anxiety disorder, $41 \%$ for depression, $32 \%$ for alcohol dependence, and $18 \%$ for cannabis dependence (Moffitt et al., 2010). Another prospective longitudinal study assessing 1420 participants for nine times from 9 through 21 years of age yielded to $61.1 \%$ for a well-specified psychiatric disorder. An additional, $21.4 \%$ had met the criteria for a not otherwise specified disorder only, increasing the cumulative prevalence for any disorder to $82.5 \%$ (Copeland et al., 2011). In the youngest cohort, the cumulative prevalence for any disorder was higher than 90\% (Copeland et al., 2011). In addition, there is evidence of a mounting epidemic of mental disorders in the last 15 years. In fact, childhood bipolar disorder increased 40fold (Moreno et al., 2007), autism increased by 20-fold, attention deficit hyperactivity disorder (ADHD) has tripled (Bloom et al., 2011), and adult bipolar disorder doubled (Ketter, 2010). These data add more confusion about the efficacy of the DSM in delineating "normality" from "pathology" as some of these statistics suggest that almost all of the population has mental disorders.

The DSM- 5 taskforce aimed to address this problem by implementing a dimensional aspect to the DSM that was supposed to reflect a continuum view of mental disorders rather than a categorical one. However, not only the taskforce failed to fully implement dimensions in the new DSM but also kept its categorical aspect and reduced the thresholds for many diagnostic criteria, which can lead to a wide increase in pathologizing previously considered "normal" individuals (Frances, 2013) making the population almost totally saturated with mental disorders. These arguments taken together raise serious questions regarding the science behind the DSM, specifically its reliability, validity and clinical utility.

In fact multiple reviews questioned the reliability and the validity of many DSM categories. For example, Blom and Oberink (2012) found that the construct validity of DSM-IV post-traumatic stress disorders (PTSD) in children and adolescents varies among different criteria: where some are highly valid (e.g., stressor criterion), while others are not (e.g., avoidance, detachment from others, and difficulty falling or staying asleep). In addition, some non-DSM criteria (e.g., guilt) had better validity than existing ones (e.g., avoidance and emotional numbing criterion). Vieta and Phillips (2007) argued that the content, concurrent, discriminant, and predictive validity of bipolar disorder are problematic suggesting a need to improve and refine diagnostic criteria. Woo and Rey (2005) found that the validity of the inattentive and hyperactive-impulsive subtypes of ADHD is not fully supported in the DSM-IV pointing to a deficit in data on treatment of the inattentive and hyperactiveimpulsive subtypes. In conjunction with these results, a metaanalysis involving 546 studies concluded that DSM-IV ADHD subtypes do not identify discrete subgroups with sufficient longterm stability to justify the classification of distinct forms of the disorder. In summary, many reviews were highly critical of the DSM, while few others supported some DSM criteria [e.g., validity of atypical depression Lam and Stewart (1996); crosscultural construct validity of ADHD in children and adolescents Willcutt (2012)].

These results taken together are particularly disappointing especially that the DSM went through multiple modifications and ameliorations in the last sixty years. In that line, Laungani (2002) argued that the popularity and extensive use of the DSM is not an indication of its reliability or validity. A theory, according to Lakatos (1970) may be true, even if no one believes in it, and it may be false, even if everyone believes in it. In addition, a low congruence was found between DSM-IV and International Diagnostic Interview (ICD-10) for many psychiatric categories including schizophrenia, schizoaffective disorder, bipolar disorder and depression (e.g., Cheniaux et al., 2009). Moreover, the rising number of individuals qualifying for at least one psychiatric disorder during lifetime renders the boundaries between "normal" and "pathological" illusive and nullifies the DSM validity and its principal reason for existence.

A second aim for the DSM is supposed to be clinical, i.e., setting a common language among clinicians in order to encourage collaboration and improving treatments for individuals with a diagnosis of a mental disorder. However, it is questionable why the DSM labels are needed to further clinical help for patients. Among the arguments for the use of psychiatric labels is that they are simple, easy, clear, quick, and convenient to use. If this argument is true, it is equally problematic as a simple and quick label can be automatically used without in-depth mental processing. This is particularly precarious specifically with the previously shown prevalence of psychiatric diagnoses among the general population.

Many scholars and clinicians have argued that psychiatric labels serve only the interests of clinicians and their professional associations (e.g., APA) as well as the pharmaceutical industry (Greenberg, 2013), whereas these labels can have devastating effects of the individuals receiving them (e.g., Frances, 2013, p. 109). In fact, labels can create self-fulfilling prophecies (Rosenthal and Fode, 1963), reducing expectations, ambitions, and changing other's perceptions and behaviors toward 
the individual carrying the label (Smith, 2002). Ben-Zeev et al. (2010) identified three types of stigma resulting from DSM diagnoses: public stigma, self-stigma, and label avoidance (Corrigan and Watson, 2002; Corrigan et al., 2004). Public stigma is the phenomenon of large social groups endorsing negative stereotypes about, and subsequently acting against, a stigmatized group: in this case, people with a diagnosis of mental disorder. Self-stigma is the loss of self-esteem and self-efficacy that occurs when the individuals internalize public stigma, which may prevent them from pursuing their life goals (Corrigan, 2006). Label avoidance is the phenomenon leading individuals to avoid mental health services in order to avoid the deleterious impact of a stigmatizing label. In addition, three processes can further exacerbate the stigma associated with psychiatric labels (Ben-Zeev et al., 2010). The first is groupness defined as the degree to which a collection of people is perceived as a unified or meaningful entity (Campbell, 1958; Hamilton and Sherman, 1996). Diagnosis distinguishes people with a mental disorder from the general population and adds to the salience of their groupness (Link and Phelan, 2001). Research has also shown a non-specific prejudice against people who have a psychiatric disorder compared with people with other health conditions (Weiner et al., 1988; Corrigan et al., 2000). In addition, diagnostic labels can serve as priming for automatic negative stereotypes (e.g., Devine, 1989; Bargh et al., 1996). Negative attitudes were also shown to be automatically activated among therapists (Abreu, 1999). Moreover, diagnostic labels of severe mental illness such as schizophrenia and psychosis seem to worsen the level of prejudice and this is even worse following a first psychotic episode (Crisp et al., 2000; Phelan et al., 2000; Birchwood et al., 2007; Lolich and Leiderman, 2008; Reed, 2008). The second is homogeneity, where out-groups members are seen more homogeneous than in-groups (Tajfel, 1978; Rothbart et al., 1997; Ashton and Esses, 1999). Categorization or groupness was also shown to increase negative stereotypes against out-group members (Link and Phelan, 2001); however, there can be causal bidirectional relationship between both (Yzerbyt et al., 1997; Crawford et al., 2002). The third is stability, meaning the traits that describe group members are believed to remain relatively stable and unchanging (Anderson, 1991; Kashima, 2000). Stability also supports the idea that psychiatric diagnoses are unchanging and that individuals are less likely to overcome them in comparison with those with physical illnesses (Weiner et al., 1988; Corrigan et al., 2000). This pessimistic view of stability is even worse in the case of severe mental illness (e.g., psychosis and schizophrenia; Harding and Zahniser, 1994). Taken together, these processes can lead to an overgeneralization error, where all members of a group are expected to manifest the same characteristics attributed to that group (Ben-Zeev et al., 2010). In addition psychiatric diagnoses when delivered rigidly, and unconditionally (without being related to specific contexts) are likely to yield to internal, stable, incontrollable and global negative attributions about the self, modifying self-concept and leading to a sense of hopelessness and learned helplessness (Seligman, 1975), which ironically was shown to be related to another popular DSM category, that is, major depressive disorder (MDD; e.g., Maiden, 1987; Healy and Williams, 1988; Duman, 2010; Vollmayr and Gass, 2013).
Taking into consideration the negative effects of psychiatric labels, which seem to outweigh any claimed benefits, it is legitimate to reconsider their clinical utility and their advantages compared to direct descriptions of the phenomenological experience of individuals seeking psychiatric or psychological help. For example, simple and direct experiential descriptors namely, emotions of sadness, worry, fear, anger, disgust, terror, and lack of energy, motivation, pleasure, and hope as well as specific thought patterns (e.g., rumination, over-generalization, and pessimism), physical sensations (e.g., fatigue, exhaustion, palpitations, fainting, and sleeplessness), cognitive processing (e.g., inattention, distraction, and memory loss), and behaviors (e.g., avoidance, isolation, or aggression) are common among individuals and provide better insight for appropriate treatment than abstract psychiatric constructs (e.g., depression, anxiety, borderline, and psychosis). In addition, the attention of the clinician must be particularly directed toward the distress and suffering experienced by the individual and toward the mental/behavioral processes that maintain and exacerbate the suffering (e.g., mind-wandering, identification with one's own thoughts, acting in opposite ways of personal values, and lack of self-acceptance and compassion).

In conjunction with their clinical utility, DSM categories are been argued to be particularly useful for pharmacological treatment. Perhaps this is the best use of psychiatric diagnoses. However, scientific research remains unclear and controversial about the benefits of a specific type of medication for a specific psychiatric diagnosis and psychotropic medications such as antidepressants and antipsychotics are been prescribed for a multitude of psychiatric disorders, including sleeping, anxiety, depression, irritability, eccentricity, temper tantrums in youth, and crankiness of old age (Frances, 2013, p. 105). In addition, the psychotropic prescribing industry is being one of the fast growing, financing a large part of DSM related research activities and financing APA itself, leading to important questions regarding the clinical necessity of such growth and its dubious ethics specifically that some of these drugs can be dangerous causing massive obesity, diabetes, heart disease, and a shortened life span (Laungani, 2002; Frances, 2013, p. 89; Greenberg, 2013). Beside these concerns, and despite of the little scientific knowledge regarding the mechanisms of actions of most of the prescribed medications, empirical findings support their utility for many individuals in specific contexts. According to that, it will be irresponsible and unethical to advise individuals stopping their medications; however, more scientific and ethical boundaries must be implemented in order to reduce unnecessary prescription and to fully explain to individuals the state of knowledge regarding the possible benefits as well as negative short and long-term effects of these medications.

Another proclaimed utility for the DSM categories is the advancement of clinical research. This is true in the scope that a large number of studies would use DSM categories. However, most of the research outcomes are measured using quantitative data, i.e., raw numbers resulting from administering specific clinical measures, e.g., Beck Depression Inventory (Beck et al., 1961, 1996; Beck and Streer, 1987), Beck Anxiety Inventory (Beck and Streer, 1993), and qualitative data, mostly obtained through clinical interviews. 
A last utility for the DSM is proclaimed to be legal as many of the diagnoses have implications within the legal system (e.g., paraphilia). However, despite their use today, it is not advisable for health science to be part of the legal debates in courts as it further undermines its primary role of treating individuals (Dawes, 1994). Other utilities are within the financial, political and social domains (e.g., health insurance); however, a review of these benefits is outside the scope of the current paper.

In summary, the DSM, when thoroughly investigated, yields to some support regarding its reliability but leads to serious questions about its validity, utility, and ethics. These findings cannot justify the overuse of DSM in mental health neither the power nor authority assigned to the DSM categories besides being only of financial and sociopolitical reasons.

\section{THE DSM: MINDFUL OR MINDLESS?}

The discussion about the DSM could be seen in the light of the concepts of mindfulness/mindlessness (Langer, 1989, 1997, 2012). Mindlessness is described as a default style of cognitive functioning in which individuals process cues from the environment in a relatively automatic but inflexible manner, without reference to novel aspects of these cues (Langer and Piper, 1987). By default, old categories and previously made distinctions are relied on uncritically, leading to rigid behavior that is rule governed rather than rule guided. In contrast, mindfulness is described as a general style or mode of functioning through which individuals actively engage in reconstructing the environment by creating new categories or distinctions, and seeking multiple perspectives, thus directing attention to new contextual cues that may be consciously controlled or manipulated as appropriate (Langer, 1989, 1997, 2012). There is growing evidence for the adaptive influence of mindful functioning on learning, health, and social behavior and, conversely, for the deleterious effects of mindlessness (e.g., Langer et al., 1978, 1985, 2012; Langer and Newman, 1979; Langer and Piper, 1987; Langer, 1989, 1992a,b, 1997, 2000, 2009, 2012).

It is been suggested that a mindful approach to language, where individuals are made aware of alternative perspectives and conceptions of what is being said or written, leads to more control and better outcomes (Langer and Piper, 1987; Langer, 1992a). The DSM is an example from the opposite side, being written using an absolute unconditional language leading to a narrow perspective of the complex human mental conditions and states by labeling some of these conditions as mental disorders. In fact, the DSM embraced a single intrapersonal definition of mental conditions, considering them as internal flaws, due to biological defects, maladaptation to the society, and/or personality difficulties, minimizing or denying at times the implication of external (environmental, interpersonal and social) factors and trivializing the lack of support facing a large number of "normal" individuals in Western societies today. For example, many of the cognitive and functional limitations perceived in the elderly can be due to non-adapted environment, an environment designed by young adults for young adults and not for the elderly (Langer, 2009). In the social sciences, this phenomenon is known as the fundamental attribution error, defined as the tendency to place a heavy emphasis on internal characteristics to explain someone else's behavior in a given situation, rather than considering external situational factors (Jones and Harris, 1967; Ross, 1977a). Fundamental attribution error is further committed when attention is fully directed toward the behavior of someone else, specifically when it is evaluated as deviant (Smith and Miller, 1979; Robinson and McArthur, 1982; Lassiter et al., 2002), when the evaluator is in an automatic (mindless) mental mode (Winter and Uleman, 1984; Uleman, 1987; Moskowitz, 1993; Newman, 1993; Carlston and Skowronski, 1994), or the evaluator lacks energy or motivation (e.g., Gilbert, 1989), and is more present in individualistic cultures (e.g., North-American) in comparison with collectivist cultures (e.g., Asian; Miller, 1984; Michael and Kaiping, 1994; Morris and Peng, 1994; Masuda and Nisbett, 2001; Langdridge and Trevor, 2004). In addition, the DSM mindlessly focuses on the inabilities or limitations of the diagnosed individuals without outweighing their shortcomings with their abilities, talents and resilience. Moreover, the DSM does not acknowledge change across time, but rather focuses on stable traits (e.g., in defining personality disorders). Being blind to the reality of continuous change is another aspect of mindlessness (Bodner and Langer, 2001). The single perspective of the DSM can exacerbate prejudice toward already negatively stereotyped individuals (e.g., individuals with a diagnosis of mental retardation; Reiss, 2000) and can contribute in justifying the under-investment of governments and health agencies in underprivileged individuals (Laungani, 2002), by rending their suffering as their own fault and responsibility and by labeling them as "abnormal and deviant" (Reiss, 2000; Pilgrim and Rogers, 2005). Such mindless application of diagnostic criteria is consistent with data on illusory correlations and psychodiagnostic tests (e.g., Chapman and Chapman, 1967, 1969; Dowling and Graham, 1976; Mirels, 1976), where illusory correlations (i.e., non-existing, over-evaluated or even opposite correlations) seem to persist even with the passage of time blinding the diagnostician in the face of contradictory reality. This phenomenon was present not only in projective and non-empirical psychological tests (e.g., Wheeler-Rorschach; Chapman and Chapman, 1969) but equally in empirical test batteries (e.g., Minnesota Multiphasic Personality Inventory - MMPI; Dowling and Graham, 1976) and was shown to be more pronounced among more experienced diagnosticians than novice ones (Dowling and Graham, 1976). A possible explanation of this phenomenon is premature cognitive commitment (Chanowitz and Langer, 1981), where previously created categories are available for mindless use (e.g., Langer and Imber, 1979), even if information is presented in a single instance (e.g., Chanowitz and Langer, 1980). This phenomenon was shown to worsen with time (i.e., with the exposure to previously learned material) as in the case of experienced diagnosticians (Dowling and Graham, 1976). This is particularly true when information is presented in an absolute, unconditional, authoritarian, and stable manner (Langer and Piper, 1987), which is the case of most psychodiagnostic tests and the DSM diagnostic criteria. Absolute diagnostic categories encourage habit, reduce uncertainty and unpleasant insecurity among diagnosticians but at the same time render it difficult for them to produce alternative, novice perceptions, distinctions or categories, making them mindlessly following previously established rules and categories without doubting or questioning these rules. In addition, 
medical residents and graduate psychology students are less prone to learn when taught with unconditional material (e.g., using DSM categories; Langer, 1997, 2000). Moreover, when presented with absolute diagnostic labels from a trusted figure of scientific authority (e.g., psychiatrist, psychologist or other mental health professionals), the individual receiving the label, even though, she is more mindful about her condition, will most likely giveup personal control accepting the label mindlessly and resigning powerlessly to its consequences, which can be devastative in many cases. In such dynamic of clinician power, authority and knowledge versus unpowered and diagnostic-naive "patient", it is highly likely that the latter will experience a lack of personal control, self-determination, in addition to the shame, stigma and infringement to self-dignity and self-esteem, with powerful physi$\mathrm{cal}$ and mental negative consequences. A counter-mechanism is to increase the control of individuals on their own health whether physical or mental, which was shown to have powerful positive consequences (Langer and Rodin, 1976; Rodin and Langer, 1977).

According to social science, the DSM can be considered as a perfect example of actor-observer bias (Kelley, 1967; Nisbett et al., 1973; Ross, 1977b; Watson, 1982; Jones and Nisbett, 1987; Gilbert, 1995), which refers to the tendency of emphasizing internal, dispositional causes (e.g., personality traits) when explaining others' behavior but considering own behavior to stem primarily from external, situational factors (e.g., being under stress). Malle et al. (2007) and Malle $(2004,2006)$ suggested a contribution of cognitive access and beliefs (e.g., the lack of context-specific information and the use of heuristics) among observers due to motivational differences with actors. This definition when applied to a noncontextually based DSM, and considering the possible motivation of the DSM users, suggests an increase in mindless use of DSM categories among mental health professionals. Laungani (2002) argued that conceptions of normality derived through the use of the DSM are, to a large extent, based on notions of social conformity. When clinicians are referring only to social conventions and previously learned information (e.g., DSM categories) in making their mind about their perceived "mentally ill" patients, they are less prone to seek novel information and less likely to have an open and curious orientation toward their patients' environment. Such mindless orientation towards the past may lead to misdiagnosis, mistreatment, and seriously compromise the therapeutic alliance between the professional and the individual seeking help.

In summary, the DSM is not only a mindless categorization of mental conditions, but also the way in which it is taught to mental health professionals encourages a mindless use of the DSM categories. That is similar to a widely diffused approach toward medical data, which is collected, justified, accepted, and used uncritically and mindlessly (Langer, 2012).

\section{BEYOND THE DSM}

Few attempts were made in Western sciences to understand human mental conditions and suffering beyond diagnostic categories. For example, Millon et al. (2010, Chap. 30) tried to extend the criteria of borderline personality disorder (as defined in the DSM) by including evolutionary, social, and cultural factors recognizing the diversity of the syndrome. However, the authors did not consider the abilities and resilience of individuals with the proclaimed syndrome.

An alternative model was also proposed in positive psychology (e.g., Peterson and Seligman, 2004) categorizing a set of 24 personality traits of "character strength and virtues." Among these traits are: creativity, curiosity, open-mindedness, wisdom, love, kindness, social intelligence, forgiveness, humility, selfregulation, and gratitude. It is noteworthy that many of these traits are related to mindfulness, whether defined according to Eastern tradition (e.g., Baer et al., 2004, 2006; Hutcherson et al., 2008) or to Western science (e.g., Langer, 1989, 1997, 2005, 2009; Langer and Moldoveanu, 2000a; Haigh etal., 2011). A mindful constructivist approach to the mental health sciences must be developed by recognizing the cultural and social embeddedness of the individual rather than using any single definition or set of criteria for human conditions (Langer and Moldoveanu, 2000b). This approach may be the key for the development of mindful clinical psychology and psychiatry. The data suggest that mindfulness is related to better outcomes for patients of therapists practicing Zen meditation (Grepmair et al., 2007). Once having realized that mindfulness can be a key element in providing better health services, the next question will be how to encourage health care professionals to learn and practice mindfulness.

Reiss (2000) suggested that mindfulness has motivational bases; the most important appears to be a desire to learn (curiosity). By engaging in mindful thinking, people can satisfy their desire for curiosity. Other motivational components are: a low need for an order (allowing for a greater creativity and mental flexibility), and a need for independence, defined as a desire for self-reliance, allowing the individual to rely on his/her own ideas and to think more freely and independently from conventions or external pressures (e.g., peer pressure and authority). These motivational bases must be used in designing and developing training programs for psychiatric residents and psychology graduate students encouraging them to uphold an open, curious and multiple perspective (mindful) attitude while investigating the conditions of their patients. Mindfulness can also be learned by imitating the behavior of a mindful therapist or supervisor. This further supports teaching mindfulness to supervisors and health decision makers.

\section{CONCLUSION}

The DSM shows both scientific and clinical limits, its wide use and the blind approval of its categories and criteria must be carefully reconsidered. When the DSM is used, it must be accompanied with alternative perspectives, emphasizing different aspects of human suffering including social, environmental, and political dimensions. Clinicians should also be mindful about the strengths and abilities of their patients and should emphasize their resilience rather than their perceived deficits. Other disciplines, namely cognitive and social sciences should be used as a solid foundation of a new scientifically driven clinical psychology and psychiatry. It is time that psychological science moves from the mindless investigation of mental disorders and psychopathology to the mindful science of mental states and consciousness. 


\section{REFERENCES}

Abreu, J. M. (1999). Conscious and nonconscious African American stereotypes: impact on first impression and diagnostic ratings by therapists. J. Consult. Clin. Psychol. 67, 387-393. doi: 10.1037/0022-006x.67. 3.387

Anderson, N. H. (1991). "Stereotype theory," in Contributions to Information Integration Theory, ed. N. H. Anderson (Hillsdale, NJ: Erlbaum), $183-240$.

Angold, A., and Costello, E. J. (1996). Toward establishing an empirical basis for the diagnosis of oppositional defiant disorder. J. Am. Acad. Child Adolesc. Psychiatry 35, 1205-1212. doi: 10.1097/00004583-19960900000018

Ashton, M. C., and Esses, V. M. (1999). Stereotype accuracy: estimating the academic performance of ethnic groups. Pers. Soc. Psychol. Bull. 25, 225-236. doi: 10.1177/0146167299025002008

Baer, R. A., Smith, G. T., and Allen, K. (2004). Assessment of mindfulness by selfreport: the Kentucky inventory of mindfulness skills. Assessment 11, 191-206. doi: $10.1177 / 107319110426802$

Baer, R. A., Smith, G. T., Hopkins, J., Krietemeyer, J., and Toney, L. (2006). Using self-report assessment methods to explore facets of mindfulness. Assessment 13, 27-45. doi: 10.1177/1073191105283504

Bargh, J. A., Chen, M., and Burrows, L. (1996). Automaticity of social behavior: direct effects of trait construct and stereotype activation on action. J. Pers. Soc. Psychol. 71, 230-244. doi: 10.1037/0022-3514.71. 2.230

Beck, A. T., and Streer, R. A. (1987). Beck Depresion Inventory Manual. San Antonio, TX: Psychological Corporation.

Beck, A. T., and Streer, R. A. (1993). Beck Anxiety Inventory Manual. San Antonio, TX: Psychological Corporation.

Beck, A. T., Steer, R. A., and Brown, G. K. (1996). Manual for the Beck Depression Inventory-II. San Antonio, TX: Psychological Corporation.

Beck, A. T., Ward, C. H., Mendelson, M., Mock, J., and Erbaugh, J. (1961). An inventory for measuring depression. Arch. Gen. Psychiatry 4, 561-571. doi: 10.1001/archpsyc.1961.01710120031004

Ben-Zeev, D., Young, M. A., and Corrigan, P. W. (2010). DSM-V and the stigma of mental illness. J. Ment. Health 19, 318-327. doi: 10.3109/09638237.2010. 492484

Birchwood, M., Trower, P., Brunet, K., Gilbert, P., Iqbal, Z., and Jackson, C. (2007). Social anxiety and the shame of psychosis: a study in first episode psychosis. Behav. Res. Ther. 45, 1025-1037. doi: 10.1016/j.brat.2006. 07.011

Bloom, B., Cohen, R., and Freeman, G. (2011). Summary Health Statistics for U.S. Children: National Health Interview Survey, 2010 (Data from the National Health Survey). Vital Health Stat. 250, 1-80.

Blom, M., and Oberink, R. (2012). The validity of the DSM-IV PTSD criteria in children and adolescents: a review. Clin. Child Psychol. Psychiatry 17, 571-601. doi: $10.1177 / 1359104511426408$

Bodner, T. E., and Langer, E. J. (2001). "Individual differences in mindfulness: the mindfulness/mindlessness scale," in 13th Annual American Psychological Society Convention, Toronto, ON.

Campbell, D. T. (1958). Common fate, similarity and other indices of the status of aggregates of persons as social entities. Behav. Sci. 3, 14-25. doi: 10.1002/bs.3830030103

Carlston, D. E., and Skowronski, J. J. (1994). Savings in the relearning of trait information as evidence for spontaneous inference generation. J. Pers. Soc. Psychol. 66 840-888. doi: 10.1037/0022-3514.66.5.840

Chanowitz, B., and Langer, E. J. (1980). "Knowing more (or less) than you can show: understanding control through the mindlessness/mindfulness distinction," in Human Helplessness, eds M. Seligman and J. Garber (New York: Academic Press), 97-130.

Chanowitz, B., and Langer, E. J. (1981). Premature cognitive commitment. J. Pers. Soc. Psychol. 41, 1051-1063. doi: 10.1037/0022-3514.41.6.1051

Chapman, L. J., and Chapman, J. P. (1967). Genesis of popular but erroneous psychodiagnostic observations. J. Abnorm. Psychol. 72, 193-204. doi: $10.1037 / \mathrm{h} 0024670$

Chapman, L. J., and Chapman, J. P. (1969). Illusory correlation as an obstacle to the use of valid psychodiagnostic signs. J. Abnorm. Psychol. 74, 271-280. doi: $10.1037 / \mathrm{h} 0027592$
Cheniaux, E., Landeira Fernandez, J., and Versiani, M. (2009). The diagnoses of schizophrenia, schizoaffective disorder, bipolar disorder and unipolar depression: interrater reliability and congruence between DSM-IV and ICD-10. Psychopathology 42, 293-298. doi: 10.1159/ 000228838

Copeland, W., Shanahan, L., Costello, E. J., and Angold, A. (2011). Cumulative prevalence of psychiatric disorders by young adulthood: a prospective cohort analysis from the great smoky mountains study. J. Am. Acad. Child Adolesc. Psychiatry 50, 252-261. doi: 10.1016/j.jaac.2010. 12.014

Corcoran, J., and Walsh, J. (2010). "Social work and the DSM: person-inenvironment versus the medical model," in Clinical Assessment and Diagnosis in Social Work Practice, 2nd Edn (New York: Oxford University Press), 11-33.

Corrigan, P. W. (2006). The impact of consumer-operated services on the empowerment and recovery of people with psychiatric disabilities. Psychiatr. Serv. 57, 1493-1496. doi: 10.1176/appi.ps.57.10.1493

Corrigan, P. W., Markowitz, F. E., and Watson, A. C. (2004). Structural levels of mental illness stigma and discrimination. Schizophr. Bull. 30, 481-491. doi: 10.1093/oxfordjournals.schbul.a007096

Corrigan, P. W., River, L. P., Lundin, R. K., Wasowski, K. U., Campion, J., Mathisen, J., et al. (2000). Stigmatizing attributions about mental illness. J. Commun. Psychol. 28, 91-102. doi: 10.1002/(SICI)1520-6629(200001)28:1<91::AIDJCOP9>3.0.CO;2-M

Corrigan, P. W., and Watson, A. C. (2002). The paradox of self-stigma and mental illness. Clin. Psychol. Sci. Pract. 9, 35-53. doi: 10.1093/clipsy. 9.1.35

Crawford, M. T., Sherman, S. J., and Hamilton, D. L. (2002). Perceived entitativity, stereotype formation, and the interchangeability of group members. J. Pers. Soc. Psychol. 83, 1076-1094. doi: 10.1037/0022-3514.83.5.1076

Crisp, A. H., Gelder, M. G., Rix, S., Meltzer, H. I., and Rowlands, O. J. (2000). Stigmatisation of people with mental illnesses. Br. J. Psychiatry 177, 4-7. doi: 10.1192/bjp.177.1.4

Crow, T. J. (1986). The continuum of psychosis and its implication for the structure of the gene. Br. J. Psychiatry 149, 419-429. doi: 10.1192/bjp.149. 4.419

Dawes, R. M. (1994). House of Cards: Psychology and Psychotherapy Built on Myth. New York, NY: The Free Press.

Devine, P. G. (1989). Stereotypes and prejudice: their automatic and controlled components. J. Pers. Soc. Psychol. 56, 5-18. doi: 10.1037/0022-3514.56.1.5

Dowling, J. F., and Graham, J. R. (1976). Illusory correlation and the MMPI. J. Pers. Assess. 40, 531-538. doi: 10.1207/s15327752j pa4005_12

Duman, C. H. (2010). "Chapter one-models of depression," in Vitamins and Hormones, ed. L. Gerald (New York: Academic Press), 1-21.

Frances, A. (2013). Saving Normal: An Insider's Revolt Against Out-of-Control Psychiatric Diagnosis, DSM-5, Big Pharma, and the Medicalization of Ordinary Life. New York: William Morrow.

Gilbert, D. T. (1989). "Thinking lightly about others: automatic components of the social inference process," in Unintended Thought, eds J. S. Uleman, and J. A. Bargh (New York: Guilford Press), 189-211.

Gilbert, D.T. (1995). "Attribution and interpersonal perception," in Advanced Social Psychology, ed. A. Tesser (New York: McGraw-Hill), 99-147.

Greenberg, G. (2013). The Book of Woe: The DSM and the Unmaking of Psychiatry. New York: Blue Rider Press.

Greener, M. (2013). DSM-5: rewriting the 'bible’. Prog. Neurol. Psychiatry 17, 24-26. doi: 10.1002/pnp.300

Grepmair, L., Mitterlehner, F., Loew, T., Bachler, E., Rother, W., and Nickel, M. (2007). Promoting mindfulness in psychotherapists in training influences the treatment results of their patients: a randomized, doubleblind, controlled study. Psychother. Psychosom. 76, 332-338. doi: 10.1159/ 000107560

Haigh, E. A. P., Moore, M., Kashdan, T., and Fresco, D. (2011). Examination of the factor structure and concurrent validity of the Langer Mindfulness/Mindlessness Scale. Assessment 18, 11-26. doi: 10.1177/10731911103 86342

Hamilton, D. L., and Sherman, S. J. (1996). Perceiving persons and groups. Psychol. Rev. 103, 336-355. doi: 10.1037/0033-295x.103. 2.336 
Harding, C. M., and Zahniser, J. H. (1994). Empirical correction of seven myths about schizophrenia with implications for treatment. Acta Psychiatr. Scand. 90, 140-146. doi: 10.1111/j.1600-0447.1994. tb05903.x

Harlow, S. D., and Linet, M. S. (1989). Agreement between questionnaire data and medical records. The evidence for accuracy of recall. Am. J. Epidemiol. 129, 233-248.

Healy, D., and Williams, J. M. (1988). Dysrhythmia, dysphoria, and depression: the interaction of learned helplessness and circadian dysrhythmia in the pathogenesis of depression. Psychol. Bull. 103, 163-178. doi: 10.1037/0033-2909. 103.2.163

Hutcherson, C., Seppala, E., and Gross, J. (2008). Loving-kindness meditation increases social connectedness. Emotion 8, 720-724. doi: 10.1037/a0013237

Jones, E. E., and Harris, V. A. (1967). The attribution of attitudes. J. Exp. Soc. Psychol. 3, 1-24. doi: 10.1016/0022-1031(67)90034-90030

Jones, E. E., and Nisbett, R. E. (1987). "The actor and the observer: divergent perceptions of the causes of behavior," in Attribution: Perceiving the Causes of Behavior, eds E. E. Jones, D. E. Kanouse, H. H. Kelley, R. E. Nisbett, S. Valins, and B. Weiner (Hillsdale, NJ: Lawrence Erlbaum Associates, Inc.), 79-94.

Kashima, Y. (2000). Maintaining cultural stereotypes in the serial reproduction of narratives. Pers. Soc. Psychol. Bull. 26, 594-604. doi: 10.1177/0146167 200267007

Keely, J. W., Burgess, D. R., and Blashfield, R. K. (2008). "Diagnostic and statistical manual of mental disorders (DSM)," in 21st Century Psychology: A Reference Handbook, eds S. F. Davis and W. Buskist (Thousand Oaks, CA: Sage Publications), 253-261.

Keller, M. B., Harrison, W., Fawcett, J. A., Gelenberg, A., Hirschfeld, R. M., Klein, D. et al. (1995). Treatment of chronic depression with sertraline or imipramine: preliminary blinded response rates and high rates of undertreatment in the community. Psychopharmacol. Bull. 31, 205-212.

Kelley, H. H. (1967). "Attribution theory in social psychology," in Nebraska Symposium on Motivation, ed. D. Levine (Lincoln: University of Nebraska Press), 129-238.

Kessler, R. C., Berglund, P., Demler, O., Jin, R., Merikangas, K. R., and Walters, E. E. (2005). Lifetime prevalence and age-of-onset distributions of DSM-IV disorder in the national comorbidity survey replication. Arch. Gen. Psychiatry 62, 593-602. doi: 10.1001/archpsyc.62.6.593

Ketter, T. (2010). Diagnostic features, prevalence, and impact of bipolar disorder. J. Clin. Psychiatry 71:e14-e14. doi: 10.4088/JCP.8125tx11c

Lakatos, I. (1970). "Falsification and the methodology of scientific programmes," in Criticism and the Growth of Knowledge, eds I. Lakatos and A. Musgrave (Cambridge: Cambridge University Press).

Lam, R. W., and Stewart, J. N. (1996). The validity of atypical depression in DSM-IV. Compr. Psychiatry 37, 375-383. doi: 10.1016/S0010-440X(96)9002090026

Langdridge, D., and Trevor, B. (2004). The fundamental attribution error: a phenomenological critique. Br. J. Soc. Psychol. 43, 357-369. doi: $10.1348 / 0144666042037962$

Langer, E. J. (1989). Mindfulness. Cambridge, MA: Da Capo.

Langer, E. J. (1992a). Interpersonal mindlessness and language. Commun. Monogr. 59, 324-327. doi: 10.1080/03637759209376274

Langer, E. J. (1992b). Matters of mind: mindfulness/mindlessness in perspective. Conscious. Cogn. 1, 289-305. doi: 10.1016/1053-8100(92) 90066-J

Langer, E. J. (1997). The Power of Mindful Learning. Reading, MA: AddisonWesley/Addison Wesley Longman.

Langer, E. J. (2000). Mindful learning. Curr. Dir. Psychol. Sci. 9, 220-223. doi: $10.1111 / 1467-8721.00099$

Langer, E. J. (2005). On Becoming an Artist: Reinventing Yourself Through Mindful Creativity. New York, NY: Ballantine Books.

Langer, E. J. (2009). Counterclockwise: Mindful Health and the Power of Possibility. New York, NY: Ballantine Books.

Langer, E. J. (2012). The mindless use of medical data. J. Bus. Res. 65, 1651-1653. doi: 10.1016/j.jbusres.2011.02.018

Langer, E. J., Bashner, R., and Chanowitz, B. (1985). Decreasing prejudice by increasing discrimination. J. Pers. Soc. Psychol. 49, 113-120. doi: 10.1037/00223514.49.1.113
Langer, E. J., Blank, A., and Chanowitz, B. (1978). The mindlessness of ostensibly thoughtful action: the role of "placebic" information in interpersonal interaction. J. Pers. Soc. Psychol. 36, 635-642. doi: 10.1037/0022-3514.36. 6.635

Langer, E. J., Cohen, M., and Djikic, M. (2012). Mindfulness as a psychological attractor: the effect on children. J. Appl. Soc. Psychol. 42, 1114-1122. doi: 10.1111/j.1559-1816.2011.00879.x

Langer, E. J., and Imber, L. (1979). When practice makes imperfect: the debilitating effects of overlearning. J. Pers. Soc. Psychol. 37, 2014-2025. doi: 10.1037/00223514.37.11.2014

Langer, E. J., and Moldoveanu, M. (2000a). The construct of mindfulness. J. Soc. Issues 56, 1-9. doi: 10.1111/0022-4537.00148

Langer, E. J., and Moldoveanu, M. (2000b). Mindfulness research and the future. J. Soc. Issues 56, 129-139. doi: 10.1111/0022-4537. 00155

Langer, E. J., and Newman, H. M. (1979). The role of mindlessness in a typical social psychological experiment. Pers. Soc. Psychol. Bull. 5, 295-298. doi: $10.1177 / 014616727900500304$

Langer, E. J., and Piper, A. I. (1987). The prevention of mindlessness. J. Pers. Soc. Psychol. 53, 280-287. doi: 10.1037/0022-3514.53. 2.280

Langer, E. J., and Rodin, J. (1976). The effects of enhanced personal responsibility for the aged: a field experiment in and institutional setting. J. Pers. Soc. Psychol. 34, 191-198. doi: 10.1037/0022-3514.34.2.191

Lassiter, F. D., Geers, A. L., Munhall, P. J., Ploutz-Snyder, R. J., and Breitenbecher, D. L. (2002). Illusory causation: why it occurs. Psychol. Sci. 13, 299-305. doi: 10.1111/j.0956-7976.2002..x

Laungani, P. (2002). Mindless psychiatry and dubious ethics. Couns. Psychol. Q. 15, 23-33. doi: 10.1080/09515070110102305

Link, B. G., and Phelan, J. C. (2001). Conceptualizing stigma. Annu. Rev. Sociol. 27, 363-385. doi: 10.1146/annurev.soc.27.1.363

Lolich, M., and Leiderman, E. (2008). Stigmatization towards schizophrenia and other mental illnesses. Vertex 19, 165-173.

Maiden, R. J. (1987). Learned helplessness and depression: a test of the reformulated model. J. Gerontol. 42, 60-64. doi: 10.1093/geronj/ 42.1.60

Malle, B. F. (2004). How the Mind Explains Behavior: Folk Explanations, Meaning, and Social Interaction. Cambridge, MA: MIT Press.

Malle, B. F. (2006). The actor-observer asymmetry in attribution: a (surprising) meta-analysis. Psychol. Bull. 132, 895-919. doi: 10.1037/0033-2909. 132.6.895

Malle, B. F., Knobe, J. M., and Nelson, S. E. (2007). Actor-observer asymmetries in explanations of behavior: new answers to an old question. J. Pers. Soc. Psychol. 93, 491-514. doi: 10.1037/0022-3514.93.4. 491.supp

Masuda, T., and Nisbett, R. E. (2001). Attending holistically vs. analytically: comparing the context sensitivity of Japanese and Americans. J. Pers. Soc. Psychol. 81, 922-934. doi: 10.1037/0022-3514.81.5.922

Michael, W. M., and Kaiping, P. (1994). Culture and cause: American and Chinese attributions for social and physical events. J. Pers. Soc. Psychol. 67, 949-971. doi: 10.1037/0022-3514.67.6.949

Miller, J. G. (1984). Culture and the development of everyday social explanation. J. Pers. Soc. Psychol. 46, 961-978. doi: 10.1037/0022-3514. 46.5.961

Millon, T., Krueger, R. F., and Simonsen, E. (2010). Contemporary Directions in Psychopathology: Scientific Foundations of the DSM-V and ICD-11. New York, NY: The Guilford Press.

Mirels, H. L. (1976). Implicit personality theory and inferential illusions. J. Pers. 44, 467-487. doi: 10.1111/j.1467-6494.1976.tb00133.x

Moffitt, T. E., Caspi, A., Taylor, A., Kokaua, J., Milne, B. J., Polanczyk, G., et al. (2010). How common are common mental disorders? Evidence that lifetime prevalence rates are doubled by prospective versus retrospective ascertainment. Psychol. Med. 40, 899-909. doi: 10.1017/S00332917 09991036

Moreno, C., Laje, G., Blanco, C., Jiang, H., Schmidt, A. B., and Olfson, M. (2007). National trends in the outpatient diagnosis and treatment of bipolar disorder in youth. Arch. Gen. Psychiatry 64, 1032-1039. doi: 10.1001/archpsyc.64. 9.1032 
Morris, M. W., and Peng, K. (1994). Culture and cause: American and Chinese attributions for social and physical events. J. Pers. Soc. Psychol. 67, 949-971. doi: 10.1037/0022-3514.67.6.949

Moskowitz, G. B. (1993). Individual differences in social categorization: the influence of personal need for structure on spontaneous trait inferences. J. Pers. Soc. Psychol. 65, 132-114. doi: 10.1037/0022-3514.65. 1.132

Newman, L. S. (1993). How individualists interpret behavior: idiocentrism and spontaneous trait inference. Soc. Cogn. 11, 243-269. doi: 10.1521/soco.1993.11.2.243

Nisbett, R. E., Caputo, C., Legant, P., and Marecek, J. (1973). Behavior as seen by the actor and as seen by the observer. J. Pers. Soc. Psychol. 27, 154-164. doi: $10.1037 / \mathrm{h} 0034779$

Peterson, C., and Seligman, M. (2004). Character Strengths and Virtues: A Handbook and Classification. Oxford: Oxford University Press.

Phelan, J. C., Link, B. G., Stueve, A., and Pescosolido, B. A. (2000). Public conceptions of mental illness in 1950 and 1996: what is mental illness and is it to be feared? J. Health Soc. Behav. 41, 188-207. doi: 10.2307/2676305

Pilgrim, D., and Rogers, A. (2005). The troubled relationship between psychiatry and sociology. Int. J. Soc. Psychiatry 51, 228-241. doi: 10.1177/0020764 005056987

Pillemer, D. B., and White, S. H. (1989). Childhood events recalled by children and adults. Adv. Child Dev. Behav. 21, 297-340. doi: 10.1016/S0065-2407(08)60291-8

Reed, S. I. (2008). First-episode psychosis: a literature review. Int. J. Ment. Health Nurs. 17, 85-91. doi: 10.1111/j.1447-0349.2008. 00515.x

Reiss, S. (2000). A mindful approach to mental retardation. J. Soc. Issues 56, 65-80. doi: 10.1111/0022-4537.00152

Robinson, J., and McArthur, L. Z. (1982). Impact of salient vocal qualities on causal attribution for a speaker's behavior. J. Pers. Soc. Psychol. 43, 236-247. doi: 10.1037/0022-3514.43.2.236

Rodin, J., and Langer, E. J. (1977). Long-term effects of a control-relevant intervention among the institutionalized aged. J. Pers. Soc. Psychol. 35, 897-902. doi: 10.1037/0022-3514.35.12.897

Rosenhan, D. L. (1973). On being sane in insane places. Science 179, 250-258. doi: 10.1126/science.179.4070.250

Rosenthal, R., and Fode, K. (1963). The effect of experimenter bias on the performance of the albino rat. Behav. Sci. 8, 183-189. doi: 10.1002/bs. 3830080302

Ross, L. (1977a). "The intuitive psychologist and his shortcomings: distortions in the attribution process," in Advances in Experimental Social Psychology, ed. L. Berkowitz (New York: Academic Press), 173-220.

Ross, L. (1977b). "The intuitive scientist and his shortcomings," in Advances in Experimental Social Psychology, ed. L. Berkowitz (New York: Academic Press), 174-221.

Rothbart, M., Davis-Stitt, C., and Hill, J. (1997). Effects of arbitrarily placed category boundaries on similarity judgments. J. Exp. Soc. Psychol. 33, 122-145. doi: 10.1006/jesp.1996.1315

Seligman, M. (1975). Helplessness. San Francisco: W. H. Freeman.

Smith, E. R., and Miller, F. D. (1979). Salience and the cognitive appraisal in emotion. J. Pers. Soc. Psychol. Bull. 48, 813-883. doi: 10.1037/0022-3514.48.4.813
Smith, R. (2002). In search of “non-disease.” Br. Med. J. 324, 883-885. doi: 10.1136/bmj.324.7342.883

Tajfel, H. (1978). Differentiation Between Social Groups: Studies in the Social Psychology of Intergroup Relations. New York: Academic Press.

Uleman, J. S. (1987). Consciousness and control: the case of spontaneous trait inferences. Pers. Soc. Psychol. Bull. 13, 337-354. doi: 10.1177/01461672 87133004

Vieta, E., and Phillips, M. (2007). Deconstructing bipolar disorder: a critical review of its diagnostic validity and a proposal for DSM-V and ICD-11. Schizophr. Bull. 33, 886-892. doi: 10.1093/schbul/sbm057

Vollmayr, B., and Gass, P. (2013). Learned helplessness: unique features and translational value of a cognitive depression model. Cell Tissue Res. 354, 171-178. doi 10.1007/s00441-013-1654-1652

Watson, D. (1982). The actor and the observer:Howare their perceptions of causality divergent? Psychol. Bull. 92, 682-700. doi: 10.1037/0033-2909.92.3.682

Weiner, B., Perry, R. P., and Magnusson, J. (1988). An attributional analysis of reactions to stigmas. J. Pers. Soc. Psychol. 55, 738-748. doi: 10.1037/00223514.55.5.738

Willcutt, E. (2012). The prevalence of DSM-IV attention-deficit/hyperactivity disorder: a meta-analytic review. Neurotherapeutics 9, 490-499. doi: 10.1007/s13311012-0135-8

Winter, L., and Uleman, J. S. (1984). When are social judgements made? Evidence for the spontaneousness of trait inferences. J. Pers. Soc. Psychol. 47, 237-252. doi: 10.1037/0022-3514.47.2.237

Woo, B. S. C., and Rey, J. (2005). The validity of the DSM-IV subtypes of attention-deficit/hyperactivity disorder. Aust. N. Z. J. Psychiatry 39, 344-353. doi: 10.1111/j.1440-1614.2005.01580.x

Yzerbyt, V. Y., Leyens, J.-P., and Schadron, G. (1997). Social judgeability and the dilution of stereotypes: the impact of the nature and sequence of information. Pers. Soc. Psychol. Bull. 23, 1312-1322. doi: 10.1177/01461672972312008

Zinbarg, R. E., Barlow, D. H., Liebowitz, M., Street, L., Broadhead, E., Katon, W., et al. (1994). The DSM-IV field trial for mixed anxiety-depression. Am. J. Psychiatry 151, 1153-1162.

Zubin, J. (1967). Classification of the behaviour disorders. Annu. Rev. Psychol. 18, 373-406. doi: 10.1146/annurev.ps.18.020167.002105

Conflict of Interest Statement: The authors declare that the research was conducted in the absence of any commercial or financial relationships that could be construed as a potential conflict of interest.

Received: 02 March 2014; accepted: 29 May 2014; published online: 17 June 2014. Citation: Khoury B, Langer EJ and Pagnini F (2014) The DSM: mindful science or mindless power? A critical review. Front. Psychol. 5:602. doi: 10.3389/fpsyg.2014.00602 This article was submitted to Psychology for Clinical Settings, a section of the journal Frontiers in Psychology.

Copyright (C) 2014 Khoury, Langer and Pagnini. This is an open-access article distributed under the terms of the Creative Commons Attribution License (CC BY). The use, distribution or reproduction in other forums is permitted, provided the original author(s) or licensor are credited and that the original publication in this journal is cited, in accordance with accepted academic practice. No use, distribution or reproduction is permitted which does not comply with these terms. 